\section{Endoscopic ultrasound-guided cholangiography and intraluminal needle puncture through a tight subhilar bile duct stricture for biliary stenting following failed ERCP}

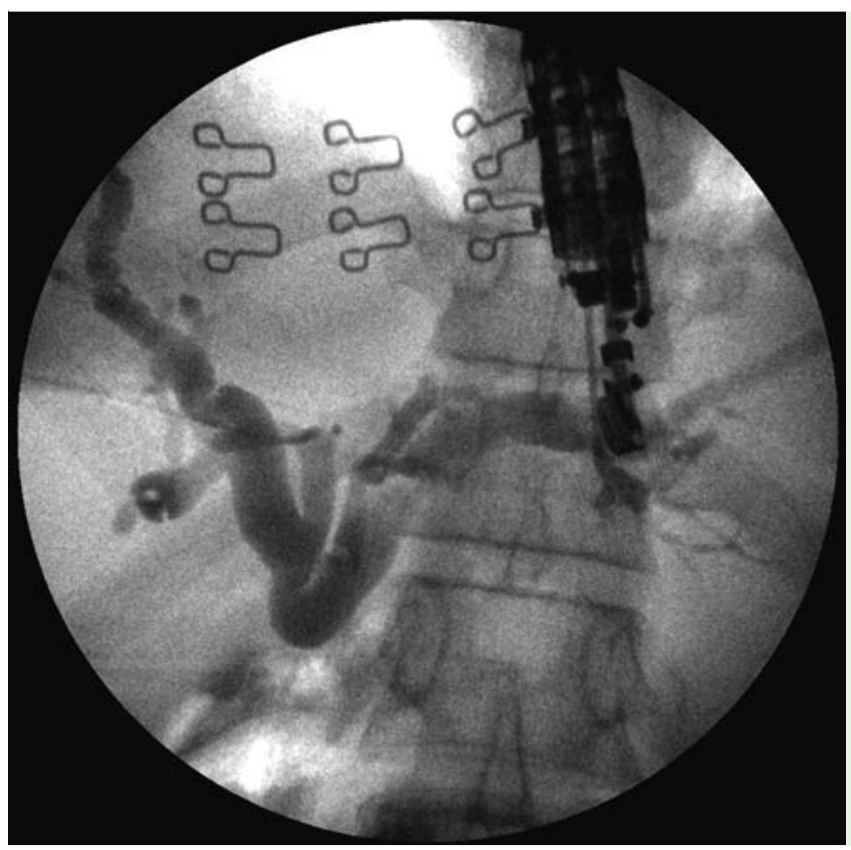

Fig. 1 Endoscopic ultrasound (EUS)-guided puncture of dilated left biliary radical showing a tight subhilar stenosis in a 39-year-old woman with obstructive jaundice, 1 month after cholecystectomy.

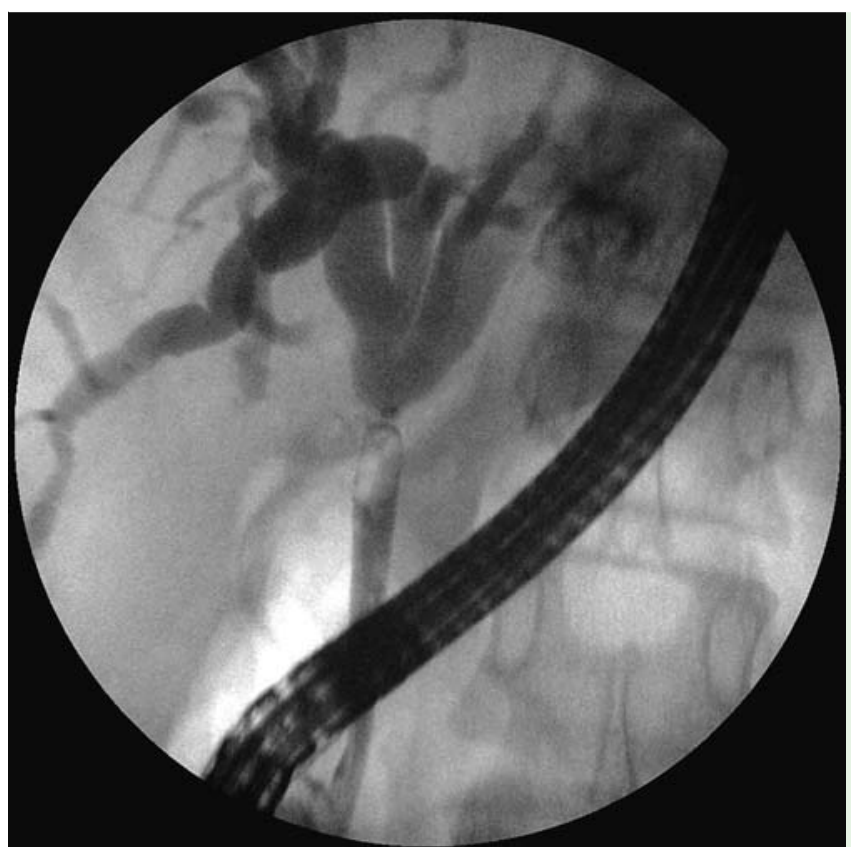

Fig. 2 Endoscopic retrograde cholangiopancreatography (ERCP) following EUSguided puncture, showing details of the stricture and biliary radicals.

Endoscopic therapy by endoscopic retrograde cholangiopancreatography (ERCP), stricture dilation, and sequential multiple stent placement is the standard treatment option for benign biliary strictures, and has favorable results [1]. Occasionally,
[2]. It is not known whether the EUS-guided rendezvous procedure also facilitates guide wire passage across difficult strictures. We report a case of post-cholecystectomy subhilar stricture in which ERCPguided passage of the guide wire across the stricture was unsuccessful. Hence, EUS-guided cholangiography was carried out followed by intraluminal needle puncture of the stricture with a 18-gauge needle device to pass the guide wire, with completion of the ERCP and stenting.

A 39-year-old woman presented with obstructive jaundice 1 month after cholecystectomy. Magnetic retrograde cholangiopancreatography (MRCP) revealed a stricture in the subhilar region. An ERCP was attempted and the cholangiogram showed a tight stricture in the subhilar region with minimal opacification of the common hepatic duct. The guide wire (.035 inches and .032 inches Terumo, Terumo Corporation, New Jersey, USA) could not be negotiated through the stricture. Endoscopic ultrasound (EUS) was done for two reasons: first, to attempt a rendezvous procedure, and second, to obtain a cholangiogram of the proximal biliary system to assist with rescue intraluminal needle puncture across the stricture at ERCP if the rendezvous procedure was not technically feasible. A19-gauge EUS fine needle aspiration (FNA) needle (Cook Medical, Winston-Salem, North Carolina, USA) was used to puncture the left hepatic system. Contrast injection showed a type I stricture ( $\bullet$ Fig. 1). However the 0.032-inch guide wire could not be passed across the stricture. Opacification of the intrahepatic biliary system allowed complete delineation of the $1.5-\mathrm{mm}$ long stricture from above ( $\bullet$ Fig. 2). There was complete cutoff at the level of the common hepatic duct, and hence we decided to abandon the rendezvous procedure and attempt ERCP-guided intraluminal needle puncture across the stricture.

During the ERCP, an Artifon suprapapillary bile duct puncture catheter (SCITECH, Sao Paulo, Brazil), was passed through the papilla and positioned fluoroscopically at the distal end of the stricture. The needle from the catheter was advanced into the stricture and sustained pressure applied in the direction of the common hepatic duct, which was visualized on the EUSguided cholangiogram. The needle easily traversed through the stricture into the common hepatic duct. A 0.032-inch guide wire was then passed into the right hepatic system ( $\bullet$ Fig.3). The stricture was dilated using a biliary dilator and a 


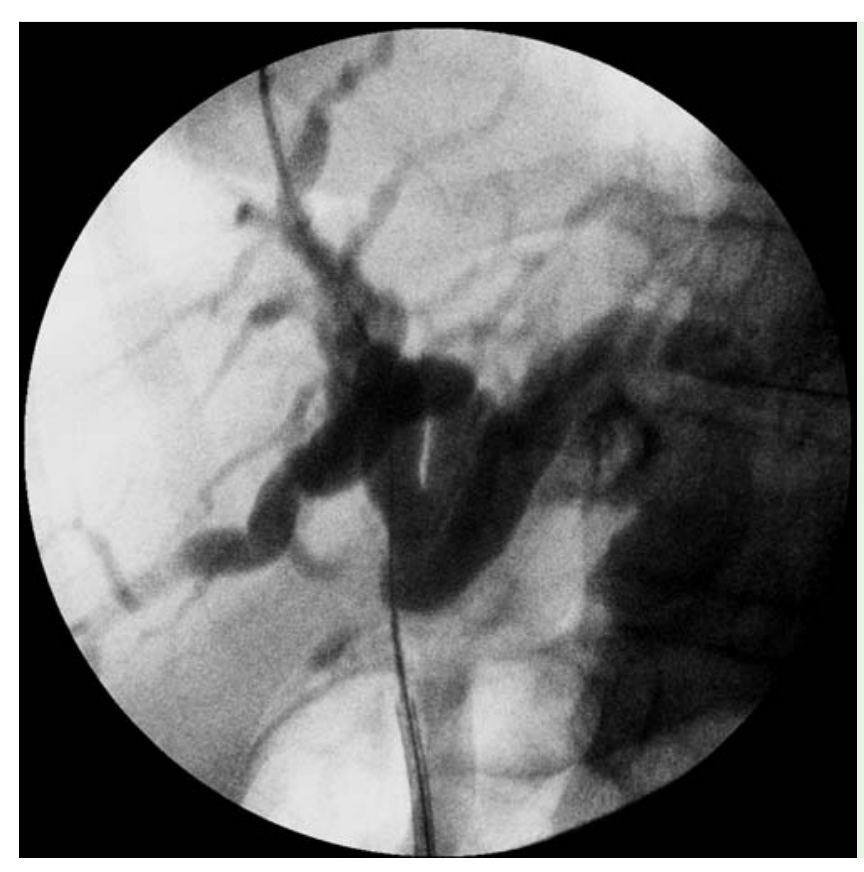

Fig. 3 The Artifon catheter with the guide wire across the stricture.

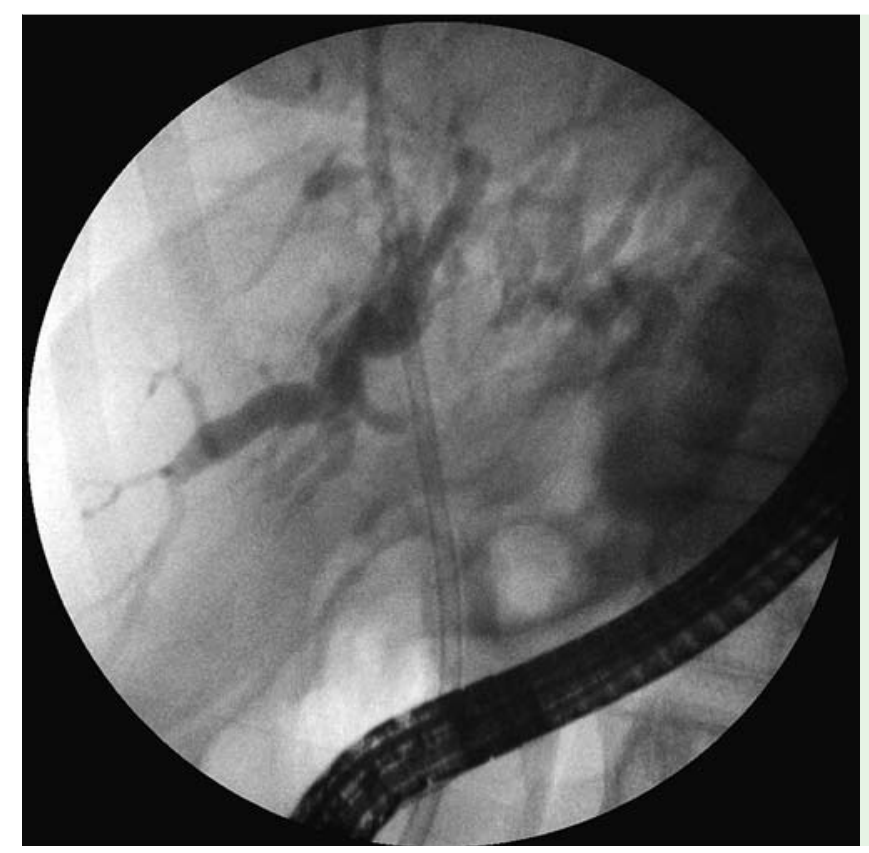

Fig.4 A 10-Fr plastic stent is seen across the stricture with good drainage.

vented in our patient by use of EUS-guided contrast injection in the intrahepatic biliary tree. The subhilar position of the stricture allowed us to pass an adequate length of the puncture catheter in the common bile duct, which we believe is critical for positioning the catheter in the required direction of puncture.

Endoscopy_UCTN_Code_TTT_1AS_2AD

\section{Competing interests: None}

\section{Dhir, S. Vivekanandarajah, S. Bhandari, M. Bapat, A. Maydeo}

Institute of Advanced Endoscopy, Mumbai, India

\section{References}

1 Costamagna G, Pandolfi $M$, Mutignani $M$ et al. Long-term results of endoscopic management of postoperative bile duct strictures with increasing numbers of stents. Gastrointest Endosc 2001; 54: 162 - 168

2 Dhir V, Kwek BEA, Bhandari S et al. EUS-guided biliary rendezvous using a short hydrophilic guidewire. J Interv Gastroenterol 2011; 1: 153-159

3 Artifon EL, Sakai P, Ishioka $S$ et al. Suprapapillary puncture of the common bile duct for selective biliary access: a novel technique. Gastointest Endosc 2007; 65: $124-$ 131

4 Gupta K, Aparicio D, Freeman ML et al. Endoscopic biliary recanalization by using a needle catheter in patients with complete ligation or stricture of the bile duct: safety and feasibility of a novel technique. Gastrointest Endosc 2011; 74: 423-428

\section{Bibliography}

Dol http://dx.doi.org/

$10.1055 / \mathrm{s}-0032-1326121$

Endoscopy 2013; 45: E5-E6

(c) Georg Thieme Verlag KG

Stuttgart · New York

ISSN 0013-726X

10 -Fr plastic biliary stent was placed into the right hepatic duct ( $\bullet$ Fig.4). There were no post-procedural complications and patient was discharged after 72 hours.

This is the first report of negotiation of a bile duct stricture using a biliary puncture catheter after EUS-guided cholangiography and direct intraluminal puncture of the stricture. The biliary puncture cathe- ter (Artifon catheter) was originally devised for EUS-guided suprapapillary transduodenal bile duct puncture to avoid cannulation through the papilla [3]. Since then, it has been used by Gupta et al for blind puncturing of common bile duct strictures after MRCP to determine the stricture characteristics [4]. We believe that blind puncture of the stricture poses a risk of perforation, which could be pre-

\section{Corresponding author}

\section{Dr V. Dhir}

Institute of Advanced Endoscopy

123, August Kranti Marg

5th Floor, Om Chambers, Kemps Corner

Mumbai 400036

India

vinaydhir@gmail.com 